\title{
Cleaning of soybean seeds using the gravity- pneumatic cleaner in the line of production soybean
}

\author{
Victor Khamyev ${ }^{1}$, Anatoly Gulyev ${ }^{1}$, Gaik Adamyan ${ }^{1, *}$, Andrey Boiko ${ }^{2}$ and Bui Quang Minh ${ }^{3}$ \\ ${ }^{1}$ Federal Scientific Agro-Engineering Center VIM, 1 Institutsky proezd, 5, Moscow, 109428, Russia. \\ ${ }^{2}$ Don State Technical University, Gagarin Square, 1, Rostov-on-Don, 344000, Russia. \\ ${ }^{3}$ Hanoi University of Agriculture, Hanoi, Vietnam.
}

\begin{abstract}
The aim of the study is determining the main agricultural technical indicators of the TS-5 gravity-pneumatic cleaner prototype as part of the soybean seed cleaning production line. It was presented the results of research of a evaluation basic indicators of the TS-5 gravitational-pneumatic cleaner in comparison with the basic version of the VIM-3 machine for cleaning soybean seeds. Comparative technical and economic results of the new machine TS - 5 and the basic variant BIM - 3 have been obtained, which allow to conclude that the developed grain cleaning line has shown high technological reliability and resource and energy efficiency.
\end{abstract}

\section{Introduction}

As part of the research, production tests were carried out on the TS-5 gravitational-cleaner as part of the technological line of soybean seeds based on production facilities, of the «AgroSoyaComplekt» LLC, partially branch «ASK-Belogorie» LLC.

Now «AgroSoyaComplekt» LLC has production facilities both in Central Russia and in the Far East of Russia, thus covering all country. This enterprise meets the requirements of the model farm from Russian standard GOST 23730-88 «Agricultural machinery. Methods of economical evaluation of universal machines and technological complexes».

The aim of the research is determining the main agricultural technical indicators of the TS5 gravity-pneumatic cleaner prototype as part of the soybean seed cleaning process line.

\section{Materials and methods}

The production line (Fig. 1) was manufactured and installed specifically for the experimental research and includes:

- loading tanker for receiving source material $\mathrm{V}=10 \mathrm{~m} 3$;

- storage - loading tanker for feeding the source material into the gravity-pneumatic cleaner $\mathrm{V}=7 \mathrm{~m} 3$;

\footnotetext{
* Corresponding author: garikbegun@yandex.ru
} 
- NZ-10 grain elevator, band-bucket type, for mixing source material from loading tanker to storage - loading tanker, capacity $10 \mathrm{t} / \mathrm{h}$ and height $12 \mathrm{~m}$;

- gravity-pneumatic cleaner TS-5 for soybean seeds;

- base platform, for material removal and loading into soft containers;

- soft containers (BIGBAG), 6 bags, four-step each with a carrying capacity of up to 2000 $\mathrm{kg}$.

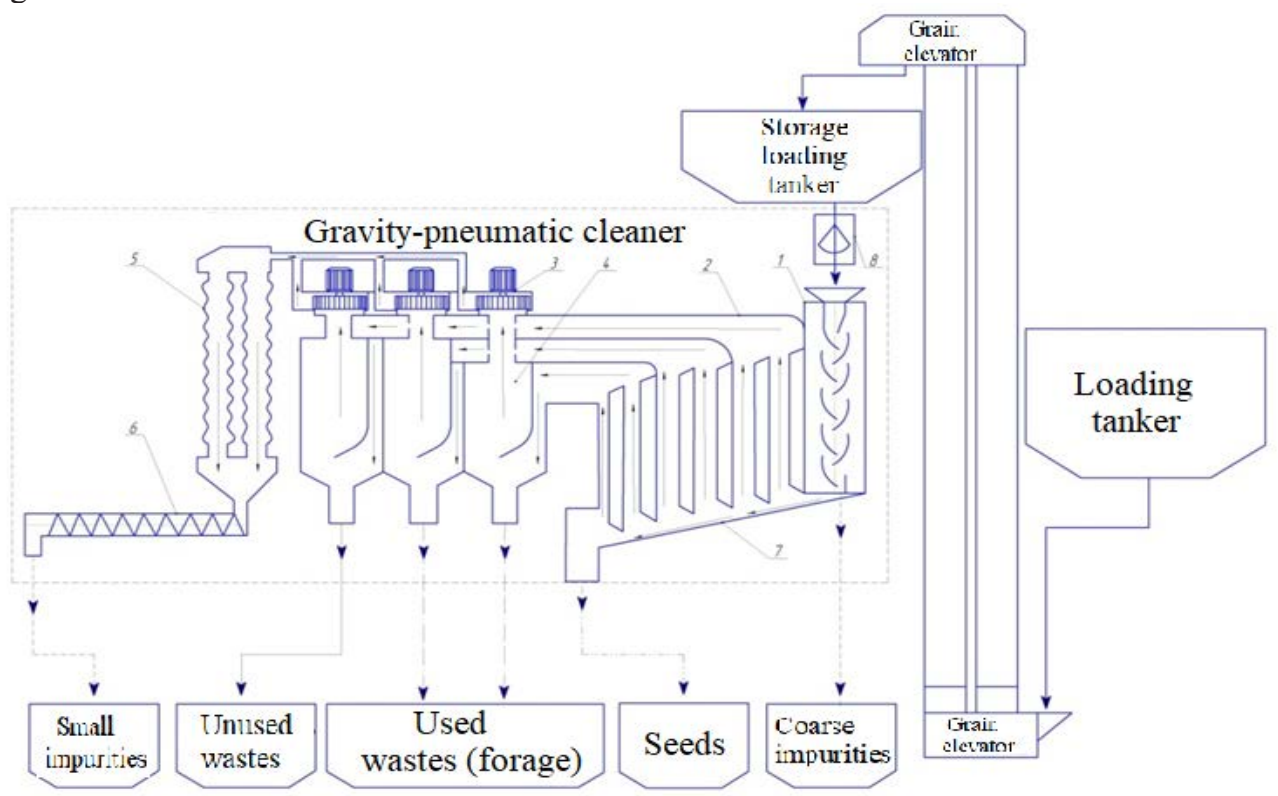

Fig. 1. Technological scheme for cleaning soybean seeds: 1 - gravity column, 2 - pneumatic channel, 3 - electric engine, 4 - sediment chamber, 5 - filters, 6 - auger conveyor , 7 - supporting grid, 8 - gate valve.

Cleaning was carried out on the following source material: soybean seeds variety «ROS» from the harvester's tanker, moisture $\mathrm{W}=18 \%$, trash impurities content $15 \%$, bulk density $740 \mathrm{~g} / \mathrm{dm} 3$, coarse impurities $5 \%$, weight of 1000 seeds - $174 \mathrm{~g}$, yield $310 \mathrm{~kg} / \mathrm{ha}$.

The method of active experiment planning was chosen to investigate the process [1]. The main parameters for theoretical studies and preliminary experiments were defined (Table 1): X - feed of the source material; X2 - air flow velocity; X3 - diameter of the outlet pipe.

The studies were carried out according to a plan for a fractional factor experiment with a variation of the investigated factors on three levels.

Table 1. Factors and levels of variation.

\begin{tabular}{|c|c|c|c|}
\hline Factors & Factors name & Levels & Values \\
\hline$X$ & Feed of the source material & $-1 \ldots 0 \ldots 1$ & $2 \ldots 4 \ldots 8$ \\
\hline$X_{2}$ & Air flow velocity & $-1 \ldots 0 \ldots 1$ & $17 \ldots 18 \ldots 19$ \\
\hline$X_{3}$ & Diameter of the outlet pipe & $-1 \ldots 0 \ldots 1$ & $10 \ldots 15 \ldots 20$ \\
\hline
\end{tabular}

The material composition was determined on the vibration classifier RPK-30 with a set of sieves, which have round holes from 1 to $10 \mathrm{~mm}$ in diameter. The average product sample weighing $1000 \mathrm{~g}$ was sifted on the classifier within 10 minutes. The hanger and fractions 
were weighed on technical scales with an accuracy of $0.01 \mathrm{~g}$. Experimental studies were carried out using a co-defined planning matrix (Table 1).

The tests were repeated three times and then, according to the planning matrix, design and regime parameters were set, which were repeated in the same repeat.

The results of experimental studies were processed using mathematical statistics methods. The Excel mathematical software package was used to process the experimental research results [2].

There are many schemes for cleaning soybean seeds, both fractional and sequential $[3,4,5]$. They are determined by the required quality indicators and environmental preferences. This process of cleaning and sorting soybean seeds is as follows: the source material is fed by the MONETOU loader to the feeding tanker (Fig. 2), from which it flows by gravity into the elevator shoe. The source material is fed and loaded into the storage and loading tanker using the grain elevator. Then the material is dosed with a gate valve and fed to the TS-5 gravity-pneumatic cleaner. The source material is loaded into the gravity column 1 .

The material moves from top to bottom in a channel with raker inside the column, the basic material passes between the fingers of the raker, and the coarse impurities come off the raker in the central channel and they are removed from the machine through a corresponding socket in the BIDBAG. Then the source material flows by gravity into the supporting grid 7 of the air channel 2 with narrowing partitions. The upward air flow generated by fans 3 releases the used (forage) and unused waste.

The cleaned material is removed from the machine via a BIGBAG connection. The impurities separated by the air currents are removed to sediment chamber 4 and discharged through the appropriate valves. The air streams passed through the fan and they are cleaned from dust in fabric material filters 5. The separated dust is collected in a special dust collector and discharged by a auger 6 through a BIGBAG spigot.

\section{Research results}

A summary test table (Table 2) and a table of comparative indicators of the technical level of the machine being tested (Table 4) have been compiled.

Based on the results of the experiment, samples were taken, the results were obtained and the characteristics of the source material and the quality of the cleaning machine were determined by the following indicators (Table 3-5): mass of 1000 seeds in each received fraction of Msr - 234.6g; purity of the cleaned material - 93.91\%; losses of seeds of the main crop in the waste $2.31 \%$; completeness of the separation of trash impurities - $93.81 \%$.

Table 2. Conditions for laboratory field and operational tests.

\begin{tabular}{|l|c|c|}
\hline \multirow{2}{*}{ Indicators } & \multicolumn{2}{|c|}{ Tests } \\
\cline { 2 - 3 } & $\begin{array}{c}\text { As the technical assign- } \\
\text { ment }\end{array}$ & operational \\
\hline Test place & $\begin{array}{l}\text { «AgroSoyaComplekt» LLC , partially branch «ASK- } \\
\text { Belogorie» LLC }\end{array}$ \\
\hline Date & no & 18.03 .2020 \\
\hline Crops & $20 / 25$ & Soybean «ROS» \\
\hline moisture, $\%$ & $10 / 20$ & $15-20$ \\
\hline Content of impurities, $\%$ & $5 / 1$ & 15 \\
\hline Also with length no more $60 \mathrm{~mm}$ & 730 & $2-6$ \\
\hline bulk density $740 \mathrm{~g} / \mathrm{dm} 3$ & & $720-750$ \\
\hline
\end{tabular}


Table 3. Technical level indicators of the machine being tested.

\begin{tabular}{|c|c|c|}
\hline \multirow[t]{2}{*}{ Indicators } & \multicolumn{2}{|c|}{ Tested machines } \\
\hline & TS-5 & VIM-3 \\
\hline \multicolumn{3}{|c|}{ Destination indicators: } \\
\hline Capacity, $\mathrm{t} / \mathrm{h}$ & 5 & 3 \\
\hline - process time & 5 & 3 \\
\hline - changeable time & 4,8 & 2,7 \\
\hline - operating time & 4,6 & 2,5 \\
\hline Specific engine power, $\mathrm{kWh}$. & 0,125 & 0,125 \\
\hline Installed power, kW. & 7,5 & 7,5 \\
\hline Coefficient of use of changeable time & 0,997 & 0,993 \\
\hline Coefficient of use operating time & 0,992 & 0,987 \\
\hline Technological service factor & 1 & 1 \\
\hline Process reliability factor & 1 & 1 \\
\hline \multicolumn{3}{|c|}{ The main quality indicators of the technological process at soybean seed cleaning: } \\
\hline Content of trash impurities, $\%$ & $0.4-5$ & $0.7-4$ \\
\hline Also with length, $\%$ & $0.3-1.5$ & $0.5-1.1$ \\
\hline Crushing of grain by machine, $\%$ & 0 & 0 \\
\hline Losses of main grain in wastes, $\%$ & $0.05-0.41$ & $0.72-0.078$ \\
\hline full extraction of weed impurities & 86.1 & 82.9 \\
\hline \multicolumn{3}{|c|}{ The technological indicators } \\
\hline Specific material capacity, $\mathrm{kg} / \mathrm{t}$ & 6.33 & 4.75 \\
\hline
\end{tabular}

Table 4. Technological characteristics of soybean seeds during cleaning on an experimental production line

\begin{tabular}{|c|c|c|c|c|c|c|c|c|c|c|c|c|c|c|}
\hline \multirow{4}{*}{ : } & \multirow{4}{*}{ 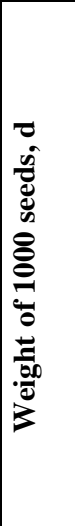 } & \multicolumn{13}{|c|}{ Main technological indicators of purified soybean seed fractions. } \\
\hline & & \multicolumn{3}{|c|}{$\begin{array}{c}\text { Fraction } \\
\text { composition } \\
\text { Soybean seeds }\end{array}$} & \multicolumn{6}{|c|}{$\begin{array}{l}\text { Statistical characteristics of soy- } \\
\text { bean seed sizes }\end{array}$} & \multicolumn{3}{|c|}{$\begin{array}{l}\text { Seed content of } \\
\text { different sizes in } \\
\text { thickness, \% }\end{array}$} & \multirow{3}{*}{ 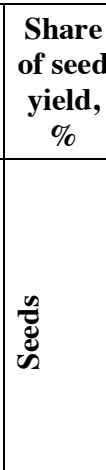 } \\
\hline & & \multirow{2}{*}{ 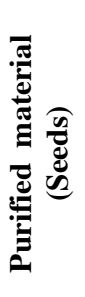 } & \multirow{2}{*}{ 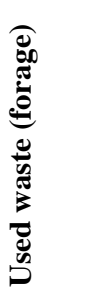 } & \multirow[t]{2}{*}{ 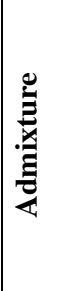 } & \multicolumn{2}{|c|}{ 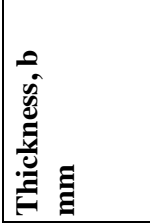 } & \multicolumn{2}{|l|}{ 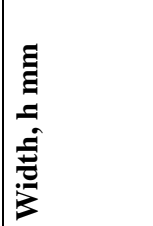 } & \multicolumn{2}{|l|}{ 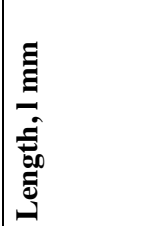 } & \multirow[t]{2}{*}{ 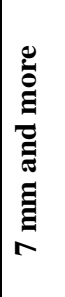 } & \multirow{2}{*}{ 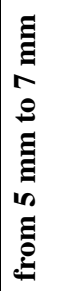 } & \multirow[t]{2}{*}{$\begin{array}{c}\Xi \\
\Xi \\
1 n \\
\varrho\end{array}$} & \\
\hline & & & & & Aver & Gb & Aver. & Gh & Aver.. & Gl & & & & \\
\hline 2 & 229,1 & 92,62 & 5,24 & 2,14 & 5,99 & 0,41 & 7,4 & 0,23 & 8,82 & 0,32 & 9,1 & 83,6 & 7,3 & 91,93 \\
\hline 4 & 232,6 & 93,91 & 3,78 & 2,31 & 6,14 & 0,38 & 7,12 & 0,57 & 8,79 & 0,46 & 8,8 & 85,1 & 6,1 & 91,04 \\
\hline 6 & 237,4 & 89,21 & 8,7 & 2,09 & 5,93 & 0,59 & 7,29 & 0,38 & 8,86 & 0,23 & 8,4 & 84,8 & 6,8 & 91,12 \\
\hline 8 & 239,3 & 87,19 & 11,94 & 2,87 & 5,98 & 0,68 & 7,17 & 0,31 & 8,73 & 0,54 & 7,8 & 87,1 & 5,1 & 90,37 \\
\hline
\end{tabular}


Table 5. Analysis of the «used waste (fodder)» fraction for further processing «extruding»

\begin{tabular}{|c|c|c|c|c|c|c|c|c|c|}
\hline \multirow[b]{2}{*}{ 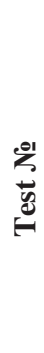 } & \multirow[b]{2}{*}{ క్ర } & \multirow[b]{2}{*}{ 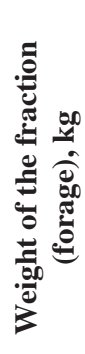 } & \multirow[b]{2}{*}{ 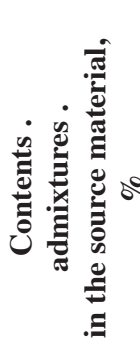 } & \multirow[b]{2}{*}{ 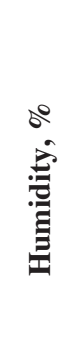 } & \multirow[b]{2}{*}{ 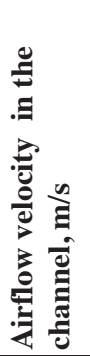 } & \multirow[b]{2}{*}{ 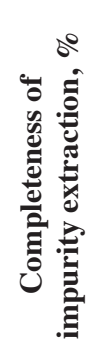 } & \multicolumn{3}{|c|}{ Waste (forage) in use" fraction } \\
\hline & & & & & & & $\begin{array}{l}\text { Amount of } \\
\text { crushed ma- } \\
\text { terial in frac- } \\
\text { tions, \% }\end{array}$ & $\begin{array}{c}\text { Number of } \\
\text { whole seeds in } \\
\text { fractions, } \\
\text { pcs./kg }\end{array}$ & $\begin{array}{c}\text { Seed } \\
\text { Losses, \% }\end{array}$ \\
\hline 1 & 2,1 & 2,62 & 2,14 & 12,1 & 17,0 & 92,62 & 97,61 & 107 & 2,39 \\
\hline 2 & 4,3 & 3,13 & 2,31 & 12,1 & 17,8 & 93,81 & 95,99 & 179 & 4,01 \\
\hline 3 & 6,2 & 2,85 & 2,09 & 12,1 & 18,6 & 89,21 & 86,36 & 611 & 13,64 \\
\hline 4 & 8,1 & 2,97 & 2,87 & 12,1 & 19,4 & 87,19 & 82,47 & 784 & 17,53 \\
\hline
\end{tabular}

On the basis of the data, the regularities of functioning of the machine under development (Fig. 2-3) as part of the soybean seed cleaning process line were obtained.

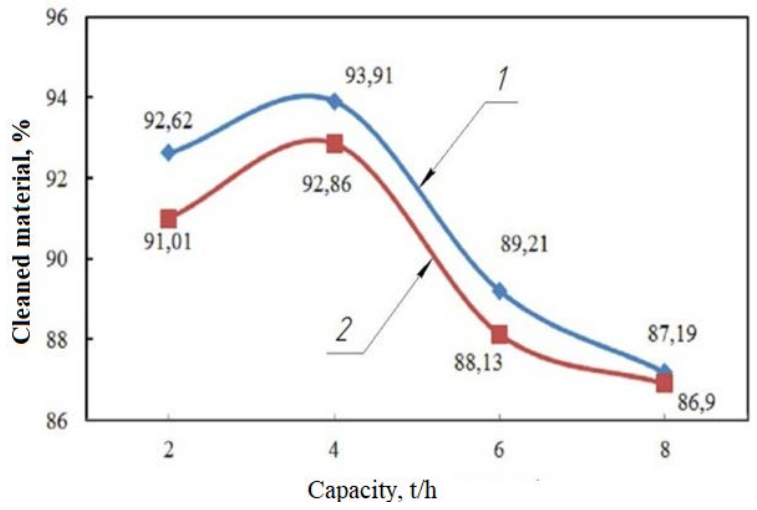

Fig. 2. Change of purified material depending on the source material capacity on TS-5 1-gravitypneumatic cleaner and on 2 - standard machine VIM-3

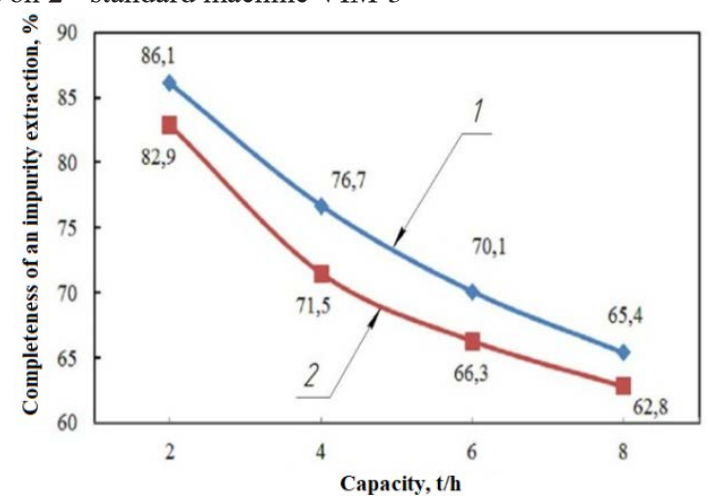

Fig. 3. Change the completeness of an impurity extraction depending on the source material capacity on 1 - gravity-pneumatic cleaner TS-5 and on 2 - standard machine VIM-3 


\section{Conclusions}

To evaluate the efficiency of the TS-5 gravity-pneumatic cleaner, we carried out a study in comparison with a typical VIM-3 machine. At the increase of productivity from 2 to $8 \mathrm{t} / \mathrm{h}$ the completeness of impurities extraction decreased at TS-5 gravity-pneumatic cleaner from $86.1 \%$ to $65.4 \%$, and VIM-3 from $82.9 \%$ to $62.8 \%$.

As it follows from fig. 3, the maximum efficiency of the purified material in the gravitational pneumatic cleaner TS-5 was $93,91 \%$ with the productivity of $4 \mathrm{t} / \mathrm{h}$, and in the machine BIM-3 the maximum efficiency of the purified material with the productivity of $4 \mathrm{t} / \mathrm{h}$ was $92,86 \%$.

TS-5 gravitational-pneumatic cleaner is the best of its known analogues - VIM-3 with productivity of $3 \mathrm{t} / \mathrm{h}$. It is important to note that the TS-5 gravity-pneumatic cleaner is universal. In the conditions of the built technological line (fig.2) TS-5 can functionally replace the line of two machines - the main and final cleaning.

In general, the developed grain cleaning line has shown high technological reliability and resource and energy efficiency.

\section{Reference}

1. Adler Yu.P., Morkova E.V., Granovsky Yu.V. Planning of experiment in search of optimal conditions. M; Nauka, 280p (1976)

2. StatSoft, Russian Portable. (2011)

3. Moskovskiy, M.N.; Boyko, A.A. Justification of different schemes of the grain cleaning unit cleaning, when receiving the seed material in the multibranch agricultural production, Engineering bulletin of the Don. №1 (2014) http:/www.ivdon.ru/magazine/archive/n1y2012/669.

4. Moskovskiy, M., Adamyan, G., Borzenko, S., Evaluation of operation indicators of the working units of transporting devices made of polymeric materials, E3S Web of Conferences, 126, pp 000332019 (2019)

5. Moskovskiy, M.N.; Khamuev, V.G.; Gerasimenko, S.A., Intensification of processes of soybean seeds separations, Electrotekhnologii i elektrotechnologii i elektrooborudovanii v agrarian complex. № 4 (37), p 143-147 (2019) 